\title{
Resposta de genótipos de trigo à inoculação de bactérias diazotróficas em condições de campo
}

\author{
Valéria Marino Rodrigues Sala(1), Elke Jurandy Bran Nogueira Cardoso(2), José Guilherme de Freitas ${ }^{(3)}$ \\ e Adriana Parada Dias da Silveira(4)
}

\begin{abstract}
(1)Escola Superior de Agricultura Luiz de Queiroz (Esalq), Av. Pádua Dias, 11, CEP 13418-900 Piracicaba, SP. E-mail: vmrsala@esalq.usp.br (2)Esalq, Dep. de Ciência do Solo. E-mail: ejbncard@esalq.usp.br (3)Instituto Agronômico (IAC), Centro de Grãos e Fibras, Caixa Postal 28, CEP13010-970 Campinas, SP. E-mail: jfreitas@iac.sp.gov.br (4)IAC, Centro de Solos e Recursos Ambientais. E-mail: apdsil@iac.sp.gov.br
\end{abstract}

\begin{abstract}
Resumo - O objetivo deste trabalho foi avaliar, em condições de campo, o efeito e a viabilidade econômica da inoculação de novos isolados homólogos de bactérias diazotróficas endofíticas, sob diferentes doses de nitrogênio, em dois genótipos de trigo, em duas localidades. Foram utilizados: três isolados de bactérias diazotróficas endofíticas (IAC-AT-8, Azospirillum brasilense; IAC-HT-11, Achromobacter insolitus; IAC-HT-12, Zoogloea ramigera), dois genótipos de trigo (ITD-19 e IAC-370) e três doses de N, na forma de uréia $\left(0,60\right.$ e $\left.120 \mathrm{~kg} \mathrm{ha}^{-1}\right)$. No estádio de quatro folhas e no perfilhamento, foram avaliados a massa de matéria seca e o $\mathrm{N}$ acumulado na parte aérea. Na colheita, foram avaliados o teor de $\mathrm{N}$, a massa de 1.000 sementes e a produtividade de grãos. A inoculação promoveu maior massa de matéria seca e $\mathrm{N}$ acumulado e aumentou a produtividade de grãos, principalmente na presença de adubo nitrogenado, com lucro para o agricultor. Entretanto, o maior aumento na produtividade de grãos foi obtido nas plantas do genótipo IAC-370, com o emprego do isolado IAC-HT-12, na ausência de N, que superou em $45 \%$ o tratamento testemunha. As respostas variaram em relação ao local de cultivo, o que sugere expressiva interação planta-bactéria-ambiente.
\end{abstract}

Termos para indexação: Triticum durum, Triticum aestivum, adubação nitrogenada, produtividade de grãos.

\section{Wheat genotypes response to inoculation of diazotrophic bacteria in field conditions}

\begin{abstract}
The aim of this work was to evaluate, in field conditions, the effect and the economic viability of inoculation of new homologous strains endophytic diazotrophic bacteria, under different nitrogen doses on two wheat genotypes. Three strains of diazotrophic bacteria (IAC-AT-8, Azospirillum brasilense; IAC-HT-11, Achromobacter insolitus; IAC-HT-12, Zoogloea ramigera), two wheat genotypes (ITD-19 and IAC-370), and three levels of nitrogen fertilizer as urea $\left(0,60 \mathrm{e} 120 \mathrm{~kg} \mathrm{ha}^{-1}\right)$ were tested. Shoot dry matter and total shoot nitrogen were evaluated, at four leaves and at tillering stages. Nitrogen concentration in the grain, 1,000 grains weight and yield were evaluated at harvest. Plants with inoculation presented increases in dry matter, $\mathrm{N}$ accumulation and grain yield, especially in combination with $\mathrm{N}$ fertilizer, bringing profit to the farmer. However, the genotype IAC-370 showed the highest increase in grain yield with the strain IAC-HT-12 in the absence of added N, exceeding the uninoculated control by $45 \%$. Responses to inoculation varied according to location, suggesting a complex interaction of plant, bacteria and the environment.
\end{abstract}

Index terms: Triticum durum, Triticum aestivum, $\mathrm{N}$ fertilizer, grain yield.

\section{Introdução}

O trigo é a segunda cultura de grãos em produção em nível mundial. A intensificação das pesquisas tem gerado grandes avanços na produtividade do trigo no Brasil (Bissoto, 2004).

O nitrogênio constitui o macroelemento mais limitante na produtividade do trigo, pois determina o número de afilhos ou perfilhos, e é essencial na fase de formação dos nós, no início do alongamento. As plantas conseguem utilizar apenas $50 \%$ do fertilizante nitrogenado, aplicado como adubo, e, metade é perdida via lixiviação e desnitrificação (Dobbelaere et al., 2002).

Somente as culturas do trigo, milho e arroz consomem aproximadamente $60 \%$ do total de fertilizantes nitrogenados utilizados no mundo (Ladha et al., 2005). Portanto, em razão da extensa área ocupada pelos cereais, aproximadamente cinco vezes a das leguminosas, a fixação biológica (FBN) associada a essas culturas torna-se de extrema importância, mesmo 
que apenas parte de suas necessidades de $\mathrm{N}$ possa ser suprida pela FBN.

Em muitos casos, a ausência de resposta à inoculação de bactérias diazotróficas em gramíneas tem sido atribuída ao uso de linhagens inadequadas. Há consenso de que o genótipo da planta é o fator-chave para obtenção dos benefícios oriundos da fixação biológica do $\mathrm{N}_{2}$, aliado à seleção de estirpes eficientes (Reis et al., 2000).

De acordo com Bashand \& Levanony (1990), aumentos moderados, em torno de $20 \%$, atribuídos à presença de bactérias diazotróficas endofíticas, seriam considerados comercialmente significativos na agricultura moderna. Em artigo de revisão, sobre 20 anos de inoculação de Azospirillum em experimentos de campo, os autores recomendam a implantação de um inoculante comercial, e concluem que é possível promover o aumento da produtividade em importantes culturas agrícolas, em diferentes solos e regiões climáticas. O sucesso da inoculação com bactérias diazotróficas endofíticas foi obtido em 60 a $70 \%$ dos experimentos já realizados (Okon \& LabanderaGonzalez, 1994). Apesar de muitos anos de pesquisa, ainda se observam respostas muito variáveis, o que mostra a importância e justifica a realização de experimentos de campo. A falta de reprodutibilidade dos resultados ocorre mesmo em ambientes mais controlados, como em casa de vegetação, o que limita a produção de um inoculante comercial (Dobbelaere et al., 2002)

O objetivo deste trabalho foi avaliar, em condições de campo, o efeito e a viabilidade econômica da inoculação de novos isolados homólogos de bactérias diazotróficas endofíticas, sob diferentes doses de $\mathrm{N}$, em dois genótipos de trigo, em duas localidades.

\section{Material e Métodos}

Os experimentos de campo foram instalados em 2002: no Centro Experimental Central do Instituto Agronômico/ APTA, em Latossolo Vermelho eutrófico típico; e na Unidade de Pesquisa e Desenvolvimento de Mococa, do Polo Regional de Desenvolvimento Tecnológico dos Agronegócios do Nordeste Paulista, em Argissolo Vermelho eutrófico típico, ambos com irrigação por aspersão.

As adubações de $\mathrm{P}, \mathrm{K}$ e micronutrientes foram feitas com base na tabela de recomendação de adubação, para a cultura do trigo irrigado para o Estado de São Paulo
(Raij et al., 1997), conforme as análises de solo dos experimentos (profundidade 0-20 cm). Características químicas do solo em Campinas: $\mathrm{MO}, 32 \mathrm{~g} \mathrm{dm}^{-3} ; \mathrm{pH}$ em $\mathrm{CaCl}_{2}$ 5,4; $\mathrm{P}, 32 \mathrm{mg} \mathrm{dm}^{-3} ; \mathrm{Ca}, 22, \mathrm{Mg}, 9, \mathrm{H}+\mathrm{Al}, 28$, soma de bases, 32 e CTC, $62 \mathrm{mmol}_{\mathrm{c}} \mathrm{dm}^{-3}$; V\% 52; B, 0,2, $\mathrm{Cu}, 6, \mathrm{Fe}, 1, \mathrm{Mn}, 31,2$ e Zn, 1,6 mg dm${ }^{-3}$. Em Mococa: MO, $28 \mathrm{~g} \mathrm{dm}^{-3} ; \mathrm{pH} \mathrm{em} \mathrm{CaCl}_{2}$ 5,2; $\mathrm{P}, 56 \mathrm{mg} \mathrm{dm}^{-3} ; \mathrm{Ca}, 36$, $\mathrm{Mg}, 14, \mathrm{H}+\mathrm{Al}, 28$, soma de bases, 55,3 e CTC, $83 \mathrm{mmol}_{\mathrm{c}} \mathrm{dm}^{-3}$; V\% 62; B, 0,18, Cu, 6, Fe, 19, Mn, 18,2 e Zn, $2,5 \mathrm{mg} \mathrm{dm}^{-3}$.

$\mathrm{O}$ delineamento experimental utilizado foi o de parcelas sub-subdivididas $\left(1,2 \times 24 \mathrm{~m}=28,8 \mathrm{~m}^{2}\right)$, com quatro repetições: na parcela, três isolados de bactérias diazotróficas endofíticas (IAC-AT-8, IAC-HT-11 e IAC- HT-12); na subparcela, dois genótipos de trigo (ITD-19, Triticum durum L. e IAC-370, Triticum aestivum hard L.); e na sub-subparcela, três doses de $\mathrm{N}$, na forma de uréia $\left(0,60\right.$ e $\left.120 \mathrm{~kg} \mathrm{ha}^{-1}\right)$. O fertilizante nitrogenado teve aplicação parcelada, e foi adicionado $70 \%$ no plantio e $30 \%$ após 30 dias da semeadura. O genótipo ITD-19 é considerado um material ineficiente e responsivo ao uso do adubo nitrogenado; é ineficiente porque, na ausência de fertilizante nitrogenado, apresenta menor produção de grãos que a média da população, e responsivo porque apresenta aumento da produção de grãos em conseqüência do $\mathrm{N}$ adicionado ao solo. O genótipo IAC-370 é considerado eficiente e responsivo.

O espaçamento utilizado entre linhas foi de $0,15 \mathrm{~m}$, com as dimensões do canteiro experimental de $4 \mathrm{~m}$ de comprimento e 1,2 m de largura.

Para o preparo dos inoculantes, os isolados foram repicados em meio de cultura líquido acrescido de $\mathrm{N}$, tendo sido: NFb (IAC-AT-8) e JNFb (IAC-HT-11 e IAC-HT-12) (Döbereiner et al., 1995). As culturas cresceram sob agitação constante durante 24 horas. Foi utilizada turfa em pó como carreador, com $10^{9}$ células $\mathrm{g}^{-1}$ de turfa, o que representou aproximadamente $30 \mathrm{~mL}$ de meio de cultura para $100 \mathrm{~g}$ de turfa. Para a contagem do número de bactérias, foram utilizados os meios NFb (IAC-AT-8) e JNFb (IAC-HT-11 e IAC-HT-12), ambos semi-sólidos e sem adição de nitrogênio. $\mathrm{O}$ inóculo foi misturado à semente no momento do plantio; foram utilizados $450 \mathrm{~g} \mathrm{ha}^{-1} \mathrm{de}$ inóculo, aproximadamente $30 \%$ a mais que a quantidade recomendada para a cultura da soja. O plantio foi realizado mecanicamente.

Os isolados utilizados: IAC-AT-8 (Azospirillum brasilense, acesso no Genbank nº DQ386149), isolado 
em meio $\mathrm{NFb}$, idealizado para o isolamento de bactérias do gênero Azospirillum; IAC-HT-11 (Achromobacter insolitus, acesso no Genbank no DQ386150) e IAC-HT-12 (Zoogloea ramigera, acesso no Genbank no- DQ389143), isolados em meio $\mathrm{JNFb}$, idealizado para o isolamento de Herbaspirillum, obtidos de raízes desinfestadas superficialmente do genótipo de trigo ITD-19. Esses isolados foram selecionados em razão de seu desempenho positivo em experimento, em condições gnotobióticas (Sala et al., 2005), e em casa de vegetação com utilização de areia esterilizada como substrato (Sala, 2002).

No estádio de quatro folhas e no perfilhamento, foram colhidos, em cada parcela experimental, $50 \mathrm{~cm}$ lineares da parte aérea das plantas de uma das linhas centrais. A massa de matéria seca foi obtida após secagem das plantas em estufa a $60^{\circ} \mathrm{C}$ com circulação de ar. Posteriormente, procedeu-se à moagem e homogeneização, para determinação da concentração de $\mathrm{N}$ pelo método micro-Kjeldahl (Bremner, 1965). Por ocasião da colheita, foram avaliados: o teor de $\mathrm{N}$ nas sementes, a produtividade de grãos e a massa de 1.000 sementes.

Os dados obtidos foram analisados, estatisticamente, pelo programa SANEST, e foi feita a análise da variância seguida da comparação das médias pelo teste de Duncan, a 5\% de probabilidade. Para comparação entre doses de nitrogênio, foram feitas regressões polinomiais.

\section{Resultados e Discussão}

No experimento realizado em Campinas, as plantas do genótipo IAC-370, no estádio de quatro folhas, não apresentaram aumento significativo da biomassa e no acúmulo de $\mathrm{N}$ com a inoculação. No estádio de perfilhamento, com a adubação de cobertura realizada, e a dose de $\mathrm{N}$ completa, todos os isolados empregados promoveram aumento significativo da biomassa e houve um incremento no $\mathrm{N}$ acumulado com a adição de $60 \mathrm{~kg} \mathrm{ha}^{-1}$ de N, em relação ao tratamento testemunha (Tabelas 1 e 2). Nesse estádio, observou-se ajuste quadrático da biomassa, em relação às doses de $\mathrm{N}$, adicionadas às plantas que receberam inóculo de isolados de bactérias diazotróficas endofíticas. Entretanto, somente na presença do isolado IAC-HT-12, foi observada essa resposta, quando avaliada a quantidade acumulada de $\mathrm{N}$.

As plantas do genótipo ITD-19, na presença do isolado IAC-HT-12, apresentaram aumento significativo da massa de matéria seca e $\mathrm{N}$ acumulado, nas doses 0 e $60 \mathrm{~kg} \mathrm{ha}^{-1}$ de $\mathrm{N}$, em ambos os estádios avaliados (Tabelas 1, 2 e 3). No estádio de perfilhamento, houve ajuste linear em relação às doses de $\mathrm{N}$ adicionadas, na presença do isolado IAC-HT-12. A adição de alta dose de $\mathrm{N}$ causou interação positiva do genótipo ITD-19 com os isolados IAC-AT-8 e IAC-HT-12, o que reverteu em aumento no crescimento e acúmulo de $\mathrm{N}$ nas plantas desse genótipo.

No experimento realizado em Mococa, na avaliação da massa da matéria seca e do $\mathrm{N}$ acumulado, na parte aérea das plantas de trigo, no estádio de quatro folhas, não houve diferenças significativas entre os isolados utilizados e a testemunha em ambos os genótipos. Entretanto, no estádio de perfilhamento, as plantas do genótipo IAC-370, foram beneficiadas pela utilização do isolado IAC-HT-12, quando se adicionou nitrogênio, e elas apresentaram maior massa de matéria seca nas

Tabela 1. Massa de matéria seca da parte aérea de dois genótipos de trigo, no estádio de perfilhamento, do experimento de campo em Campinas, SP, no ano agrícola de 2002, em função de três doses de N, sem e com inoculação de isolados de bactérias diazotróficas endofíticas. Média de quatro repetições ${ }^{(1)}$.

\begin{tabular}{|c|c|c|c|c|c|}
\hline \multirow[t]{2}{*}{ Genótipo/isolado } & \multicolumn{3}{|c|}{ Doses de $\mathrm{N}\left(\mathrm{kg} \mathrm{ha}^{-1}\right)$} & \multirow[t]{2}{*}{ Equação de regressão } & \multirow[t]{2}{*}{$\mathrm{R}^{2}$} \\
\hline & 0 & 60 & 120 & & \\
\hline & \multicolumn{5}{|c|}{ Massa de matéria seca (g m linear ${ }^{-1}$ ) } \\
\hline IAC-370/8AT & $97,03 \mathrm{ab}$ & $127,83 \mathrm{a}$ & $109,42 \mathrm{a}$ & $y=97,03+0,923 x-0,0068 x^{2}$ & 1,00 \\
\hline IAC-370/11HT & $94,31 \mathrm{ab}$ & $136,77 \mathrm{a}$ & $116,84 a$ & $y=94,31+1,227 x-0,0086 x^{2}$ & 1,00 \\
\hline IAC-370/12HT & $79,73 b$ & $144,08 \mathrm{a}$ & $107,18 \mathrm{a}$ & $y=79,73+1,916 x-0,014 x^{2}$ & 1,00 \\
\hline IAC-370/TEST & $115,26 \mathrm{a}$ & $94,07 \mathrm{~b}$ & $102,33 a$ & ns & ns \\
\hline ITD-19/8AT & $117,20 \mathrm{ab}$ & $105,18 b$ & $160,81 \mathrm{a}$ & $y=117+0,7583 x+0,0093 x^{2}$ & 1,00 \\
\hline ITD-19/12HT & $130,20 \mathrm{a}$ & $149,10 \mathrm{a}$ & $162,62 \mathrm{a}$ & $y=131+0,2667 x$ & 0,98 \\
\hline ITD-19/TEST & $77,88 \mathrm{c}$ & $87,68 b$ & $118,58 \mathrm{~b}$ & $y=74,363+0,3393 x$ & 0,92 \\
\hline
\end{tabular}

(1)Letras iguais não diferem entre si pelo teste de Duncan, a 5\% de probabilidade; as letras comparam os valores nas colunas, entre os isolados, dentro da mesma dose de $\mathrm{N}$ e do mesmo genótipo; os coeficientes de variação relativos a isolados, genótipos e doses foram 5,5, 8,0 e $16,6 \%$, respectivamente. 
doses de 60 e $120 \mathrm{~kg} \mathrm{ha}^{-1}$ de $\mathrm{N}$, e aumento do $\mathrm{N}$ acumulado, na dose de $120 \mathrm{~kg} \mathrm{ha}^{-1}$, em relação ao tratamento testemunha (Tabelas 4 e 5). Em relação às doses de $\mathrm{N}$ empregadas, houve ajuste quadrático para todos os tratamentos utilizados, com um pico de produção de biomassa, em média de $100 \mathrm{~kg} \mathrm{ha}^{-1}$; entretanto, para $\mathrm{N}$ acumulado, o ajuste foi linear.

No genótipo ITD-19, sem adição de N, as plantas que não receberam inóculo apresentaram maior massa de matéria seca e $\mathrm{N}$ acumulado do que os tratamentos com bactérias diazotróficas, o que demonstra influência negativa da inoculação (Tabela 4). Já foi observado que na ausência de adubo nitrogenado a inoculação pode causar decréscimo na massa de matéria seca da parte aérea, em relação à testemunha (Didonet et al., 2000). O mesmo autor atribuiu esse efeito a um possível aumento no crescimento das raízes, em relação à parte aérea e, também, já foi demonstrado que os isolados utilizados nesse experimento aumentaram o crescimento das raízes em condições gnotobióticas (Sala et al., 2005). Uma explicação para os benefícios causados por essas bactérias pode ser sua capacidade de síntese de fitormônios. As auxinas são os fitormônios mais comumente sintetizados por diversos grupos de microrganismos, dos quais o principal é o ácido indol acético (AIA), o que, inclusive, já foi observado em cultura pura de células de isolados de bactérias, pertencentes aos gêneros Azospirillum, Achromobacter e Zoogloea (Tsavkelova et al., 2006).

Outra explicação é a de que as bactérias diazotróficas de plantas não leguminosas não contribuem com quantidades suficientes de $\mathrm{N}_{2}$ fixado,

Tabela 2. Nitrogênio acumulado de dois genótipos de trigo, no estádio de perfilhamento, do experimento de campo em Campinas, SP, no ano agrícola de 2002, em função de três doses de N, sem e com inoculação de isolados de bactérias diazotróficas endofíticas. Média de quatro repetições ${ }^{(1)}$.

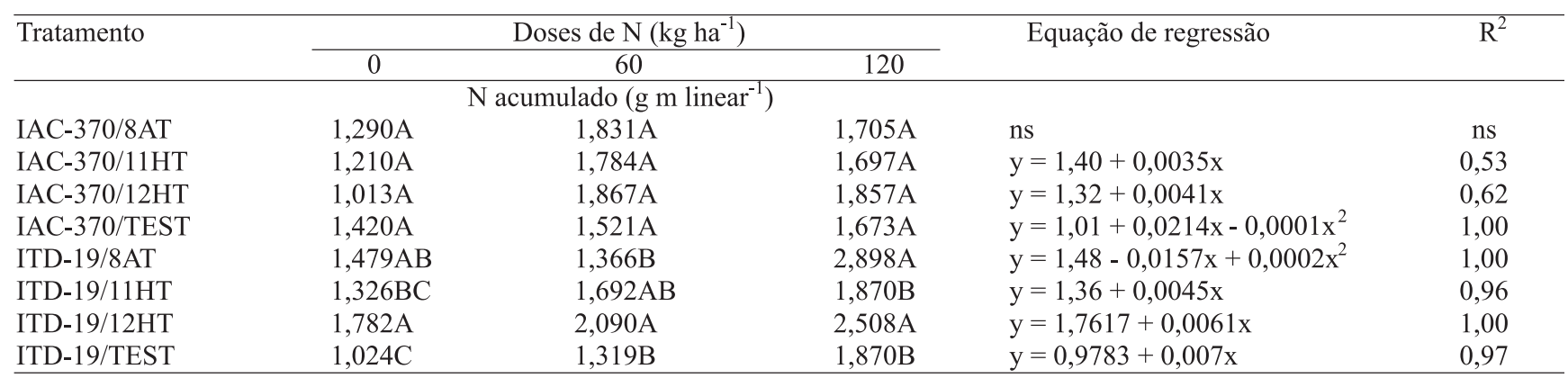

${ }^{(1)}$ Letras iguais não diferem entre si pelo teste de Duncan, a 5\% de probabilidade; as letras comparam os valores nas colunas, entre os isolados, dentro da mesma dose de $\mathrm{N}$ e do mesmo genótipo; os coeficientes de variação relativos a isolados, genótipos e doses foram 5,4, 13,3 e 16,8\%, respectivamente.

Tabela 3. Massa de matéria seca e N acumulado na parte aérea no genótipo de trigo ITD-19, no estádio de quatro folhas, do experimento de campo em Campinas, SP, no ano agrícola de 2002, em função de três doses de N, sem e com inoculação de isolados de bactérias diazotróficas endofíticas. Média de quatro repetições ${ }^{(1)}$.

\begin{tabular}{|c|c|c|c|c|c|}
\hline \multirow[t]{2}{*}{ Tratamento } & \multicolumn{3}{|c|}{ Doses de $\mathrm{N}\left(\mathrm{kg} \mathrm{ha}^{-1}\right)$} & \multirow[t]{2}{*}{ Equação de regressão } & \multirow[t]{2}{*}{$\mathrm{R}^{2}$} \\
\hline & 0 & 60 & 120 & & \\
\hline \multicolumn{6}{|c|}{ Massa de matéria seca $\left(\mathrm{g} \mathrm{m}\right.$ linear $\left.{ }^{-1}\right)$} \\
\hline ITD-19/8AT & $8,53 \mathrm{~B}$ & $9,86 \mathrm{~B}$ & $16,80 \mathrm{~A}$ & $y=7,601+0,0688 x$ & 0,87 \\
\hline ITD-19/11HT & $9,33 \mathrm{~B}$ & $9,80 \mathrm{~B}$ & $8,45 \mathrm{~B}$ & ns & ns \\
\hline ITD-19/12HT & $12,86 \mathrm{~A}$ & $15,13 \mathrm{~A}$ & $10,46 \mathrm{~B}$ & $y=2,865+0,0956 x-0,0009 x^{2}$ & 1,00 \\
\hline ITD-19/TEST & $7,00 \mathrm{~B}$ & $8,13 \mathrm{~B}$ & $11,65 \mathrm{~B}$ & $y=6,603+0,0387 x$ & 0,92 \\
\hline \multicolumn{6}{|c|}{$\mathrm{N}$ acumulado ( $\mathrm{g} \mathrm{m}$ linear $\left.{ }^{-1}\right)$} \\
\hline ITD-19/8AT & $0,340 \mathrm{BC}$ & $0,421 \mathrm{~B}$ & $0,815 \mathrm{~A}$ & $y=0,341-0,0013 x+0,00004 x^{2}$ & 1,00 \\
\hline ITD-19/11HT & $0,464 \mathrm{AB}$ & $0,521 \mathrm{AB}$ & $0,450 \mathrm{~B}$ & ns & ns \\
\hline ITD-19/12HT & $0,538 \mathrm{~A}$ & $0,691 \mathrm{~A}$ & $0,476 \mathrm{~B}$ & $y=0,538+0,0056 x-0,00005 x^{2}$ & 1,00 \\
\hline ITD-19/TEST & $0,274 \mathrm{C}$ & $0,394 \mathrm{~B}$ & $0,585 \mathrm{~B}$ & $y=0,262+0,0026 x$ & 0,98 \\
\hline
\end{tabular}

(1)Letras iguais não diferem entre si pelo teste de Duncan, a 5\% de probabilidade; as letras comparam os valores nas colunas, entre os isolados, dentro da mesma dose de $\mathrm{N}$; para massa de matéria seca os coeficientes de variação relativos a isolados, genótipos e doses foram 6,7, 20,3 e 24,5\%, respectivamente e para $\mathrm{N}$ acumulado foram $8,6,16,0$ e $25,5 \%$, respectivamente. 
para garantir produtividade máxima (Baldani \& Baldani, 2005), e que a ausência de $\mathrm{N}$ pode representar um alto custo da associação para a planta, em condição de baixo nível de $\mathrm{N}$ no solo. Uma vez que essas bactérias são extremamente dependentes das fontes de carbono disponibilizadas pela planta, todos os fatores que a afetam influenciam as bactérias a ela associadas (Hallmann et al., 1997).

Quando foram adicionados $60 \mathrm{~kg} \mathrm{ha}^{-1} \mathrm{de} \mathrm{N}$, nas plantas do genótipo ITD-19, o isolado IAC-HT-11 propiciou aumento da massa de matéria seca e $\mathrm{N}$ acumulado, tendo-se observado ajuste quadrático em relação às doses de $\mathrm{N}$ adicionadas, na presença do mesmo isolado (Tabelas 4 e 5). Já foi observado por Bertrand et al. (2000) que um isolado do gênero Achromobacter, obtido de plantas de canola, estimulou o sistema de transporte de íons pelas raízes, o que proporcionou maior absorção de nitrogênio.

Em Campinas, as plantas do genótipo IAC-370 apresentaram aumento significativo da produção, na presença do isolado IAC-HT-12, nas doses 0 e $120 \mathrm{~kg} \mathrm{ha}^{-1}$ de $\mathrm{N}$, e promoveram aumentos de aproximadamente $1.000 \mathrm{~kg} \mathrm{ha}^{-1} \mathrm{em}$ ambas as situações, o que representa um incremento de 45 e $27 \%$ respectivamente, em relação à testemunha (Tabela 6). Porém, nesse genótipo não se tinha constatado efeito benéfico da inoculação sobre a biomassa, na presença desse isolado (Tabela 1). Entretanto, pode ter havido maior crescimento das raízes em relação à parte aérea, o que pode ter propiciado o aumento na produtividade, ou ainda, menor investimento em biomassa, em benefício do grão, como demonstrado por Didonet et al. (2000).

Tabela 4. Massa da matéria seca da parte aérea de dois genótipos de trigo, no estádio de perfilhamento, do experimento de campo em Mococa, SP, no ano agrícola de 2002, em função de três doses de N, sem e com inoculação de isolados de bactérias diazotróficas endofíticas. Média de quatro repetições ${ }^{(1)}$.

\begin{tabular}{|c|c|c|c|c|c|}
\hline \multirow[t]{2}{*}{ Tratamento } & \multicolumn{3}{|c|}{ Doses de $\mathrm{N}\left(\mathrm{kg} \mathrm{ha}^{-1}\right)$} & \multirow[t]{2}{*}{ Equação de regressão } & \multirow[t]{2}{*}{$\mathrm{R}^{2}$} \\
\hline & 0 & 60 & 120 & & \\
\hline \multicolumn{6}{|c|}{ Massa de matéria seca ( $\mathrm{g} \mathrm{m}$ linear $\left.{ }^{-1}\right)$} \\
\hline IAC-370/8AT & $58,83 \mathrm{AB}$ & $135,46 \mathrm{~B}$ & $143,05 \mathrm{~B}$ & $y=58,83+1,852 x-0,009 x^{2}$ & 1,00 \\
\hline IAC-370/11HT & $46,41 \mathrm{~B}$ & $129,68 \mathrm{~B}$ & $159,99 \mathrm{AB}$ & $y=46,41+1,829 x-0,007 x^{2}$ & 1,00 \\
\hline IAC-370/12HT & $61,95 \mathrm{AB}$ & $159,65 \mathrm{~A}$ & $174,06 \mathrm{~A}$ & $y=61,96+2,322 x-0,011 x^{2}$ & 1,00 \\
\hline IAC-370/TEST & $72,70 \mathrm{~A}$ & $129,85 \mathrm{~B}$ & $138,57 \mathrm{~B}$ & $y=72,70+1,356 x-0,006 x^{2}$ & 1,00 \\
\hline ITD-19/8AT & $44,02 \mathrm{~B}$ & $105,74 \mathrm{~B}$ & $143,69 \mathrm{AB}$ & $\mathrm{y}=47,98+0,831 \mathrm{x}$ & 0,98 \\
\hline ITD-19/11HT & $50,49 \mathrm{~B}$ & $130,51 \mathrm{~A}$ & $129,45 \mathrm{~B}$ & $y=50,49+2,009 x-0,011 x^{2}$ & 1,00 \\
\hline ITD-19/12HT & $45,28 \mathrm{~B}$ & $102,89 \mathrm{~B}$ & $156,35 \mathrm{~A}$ & $y=45,97+0,925 x$ & 0,99 \\
\hline ITD-19/TEST & $81,59 \mathrm{~A}$ & $101,86 \mathrm{~B}$ & $145,18 \mathrm{AB}$ & $y=77,75+0,529 x$ & 0,96 \\
\hline
\end{tabular}

${ }^{(1)}$ Letras iguais não diferem entre si pelo teste de Duncan, a $5 \%$ de probabilidade; as letras comparam os valores nas colunas, entre os isolados, dentro da mesma dose de $\mathrm{N}$ e do mesmo genótipo; os coeficientes de variação relativos a isolados, genótipos e doses foram 7,7, 5,4 e 14,6\%, respectivamente.

Tabela 5. Nitrogênio acumulado de dois genótipos de trigo, no estádio de perfilhamento, do experimento de campo em Mococa, SP, no ano agrícola de 2002, em função de três doses de N, sem e com inoculação de isolados de bactérias diazotróficas endofíticas. Média de quatro repetições ${ }^{(1)}$.

\begin{tabular}{|c|c|c|c|c|c|}
\hline \multirow[t]{2}{*}{ Tratamento } & \multicolumn{3}{|c|}{ Doses de $\mathrm{N}\left(\mathrm{kg} \mathrm{ha}^{-1}\right)$} & \multirow{2}{*}{ Equação de regressão } & \multirow[t]{2}{*}{$\mathrm{R}^{2}$} \\
\hline & 0 & 60 & 120 & & \\
\hline \multicolumn{6}{|c|}{$\mathrm{N}$ acumulado ( $\mathrm{g}$ m linear $\left.{ }^{-1}\right)$} \\
\hline IAC-370/8AT & $0,771 \mathrm{~A}$ & $1,819 \mathrm{AB}$ & $2,453 \mathrm{~B}$ & $\mathrm{y}=0,840+0,014 \mathrm{x}$ & 0,98 \\
\hline IAC-370/11HT & $0,659 \mathrm{~A}$ & 1,649B & $2,957 \mathrm{~A}$ & $y=0,606+0,0191 x$ & 0,99 \\
\hline IAC-370/12HT & $0,788 \mathrm{~A}$ & $2,066 \mathrm{~A}$ & $3,034 \mathrm{~A}$ & $y=0,839+0,0187 x$ & 0,99 \\
\hline IAC-370/TEST & $0,900 \mathrm{~A}$ & $1,676 \mathrm{AB}$ & $2,166 \mathrm{~B}$ & $y=0,948+0,0105 x$ & 0,98 \\
\hline ITD-19/8AT & $0,481 \mathrm{~B}$ & $1,383 \mathrm{AB}$ & $2,414 \mathrm{~A}$ & $y=0,459+0,0161 x$ & 0,99 \\
\hline ITD-19/11HT & $0,591 \mathrm{~B}$ & $1,757 \mathrm{~A}$ & $2,256 \mathrm{~A}$ & $y=0,591+0,025 x-0,00009 x^{2}$ & 1,00 \\
\hline ITD-19/12HT & $0,590 \mathrm{~B}$ & $1,519 \mathrm{AB}$ & $2,622 \mathrm{~A}$ & $y=0,561+0,0169 x$ & 0,99 \\
\hline ITD-19/TEST & $1,074 \mathrm{~A}$ & $1,252 \mathrm{~B}$ & $2,348 \mathrm{~A}$ & $y=1,074-0,005 x+0,00013 x^{2}$ & 1,00 \\
\hline
\end{tabular}

${ }^{(1)}$ Letras iguais não diferem entre si pelo teste de Duncan, a $5 \%$ de probabilidade; as letras comparam os valores nas colunas, entre os isolados, dentro da mesma dose de $\mathrm{N}$ e do mesmo genótipo; os coeficientes de variação relativos a isolados, genótipos e doses foram $6,7,8,4$ e $16,2 \%$, respectivamente. 
No genótipo IAC-370, na presença do isolado IAC-HT-12, a produtividade na ausência de $\mathrm{N}$ foi praticamente igual, com $60 \mathrm{~kg} \mathrm{ha}^{-1}$ de $\mathrm{N}$, o que demonstra potencial de utilização desse isolado para economia do $\mathrm{N}$ aplicado. Também, na presença do isolado IAC-HT-12, observou-se que as quantidades de $\mathrm{N}$ empregadas não foram um fator limitante para obtenção de benefícios propiciados por esse isolado (Tabela 6).

Organismos do gênero Zoogloea são capazes de fixar $\mathrm{N}_{2}$ e já foram isolados das raízes da gramínea Leptochloa fusca (Bilal \& Malik, 1987), e foi o grupo predominantemente encontrado em plantas de arroz (Hashidoko et al., 2002). Também, já foi observado que um isolado de Zoogloea sp. aumentou a produtividade de grãos de duas variedades de arroz (Mirza et al., 2006).

Nas plantas da cultivar ITD-19, na dose de $120 \mathrm{~kg} \mathrm{ha}^{-1}$ de $\mathrm{N}$, houve incremento de aproximadamente $400 \mathrm{~kg}$ na produtividade na presença do isolado IAC-HT-11, ganho de $10 \%$ em relação ao tratamento testemunha. Também, esse isolado promoveu maior produtividade do genótipo ITD-19, comparado ao genótipo IAC-370, em todas as doses de $\mathrm{N}$ empregadas (Tabela 6).

Independentemente da dose ou cultivar utilizada, a massa de 1.000 grãos foi influenciada pelo emprego dos isolados testados (Tabela 7), e as sementes das plantas com a inoculação apresentaram maior massa que as da testemunha, o que pode ter ocorrido em razão da melhor distribuição do $\mathrm{N}$ na planta e demonstra melhor aproveitamento da biomassa gerada, em benefício da produção de grãos (Didonet et al., 2000). O teor de N no grão não foi influenciado pelos isolados utilizados, porém o isolado IAC-HT-12 promoveu maior quantidade acumulada de $\mathrm{N}$ (Tabela 7).

$\mathrm{Na}$ análise da produtividade, no experimento realizado em Mococa, no genótipo IAC-370 (Tabela 8), somente houve efeito benéfico da inoculação quando se adicionaram $120 \mathrm{~kg} \mathrm{ha}^{-1} \mathrm{de} \mathrm{N}$, e os tratamentos com os isolados IAC-AT-8 e IAC-HT-11 foram superiores à testemunha, com aumento na produtividade de 20 e $26 \%$, respectivamente. Observou-se regressão linear em relação às doses empregadas, na presença do isolado IAC-AT-8, enquanto os demais tratamentos tiveram ajuste quadrático, com ponto de máxima em torno de $100 \mathrm{~kg} \mathrm{ha}^{-1}$ de $\mathrm{N}$.

No genótipo IAC-370, o emprego do isolado IAC-HT-12 não propiciou maior produtividade em relação ao tratamento testemunha, entretanto, como ocorrido no experimento realizado em Campinas (Tabela 6), na presença de adubo nitrogenado, esse genótipo foi mais beneficiado por esse isolado do que o genótipo ITD-19 (Tabela 8).

No genótipo ITD-19, assim como no IAC-370, na ausência de fertilizante nitrogenado, não houve efeito benéfico da inoculação para a produtividade de grãos. Porém, quando se adicionou N, na dose de $60 \mathrm{~kg} \mathrm{ha}^{-1}$, e se utilizaram os isolados IAC-AT-8 e IAC-HT-11, houve incremento de aproximadamente $20 \%$ na produtividade e, também, com a adição $120 \mathrm{~kg} \mathrm{ha}^{-1}$ de $\mathrm{N}$ e o isolado IAC-AT-8, houve incremento de $14 \%$ em relação à testemunha (Tabela 8 ).

No experimento realizado em Mococa, só se obteve aumento significativo na produtividade, em razão da inoculação, no genótipo IAC-370, com a adição de

Tabela 6. Produtividade de dois genótipos de trigo, do experimento de campo em Campinas, SP, no ano agrícola de 2002, em função de três doses de N, sem e com inoculação de isolados de bactérias diazotróficas endofíticas. Média de quatro repetições ${ }^{(1)}$.

\begin{tabular}{|c|c|c|c|c|c|}
\hline \multirow[t]{2}{*}{ Tratamento } & \multicolumn{3}{|c|}{ Doses de N $\left(\mathrm{kg} \mathrm{ha}^{-1}\right)$} & \multirow[t]{2}{*}{ Equação de regressão } & \multirow[t]{2}{*}{$\mathrm{R}^{2}$} \\
\hline & 0 & 60 & 120 & & \\
\hline \multicolumn{6}{|c|}{ Produtividade $\left(\mathrm{kg} \mathrm{ha}^{-1}\right)$} \\
\hline IAC-370/8AT & $2.024 \mathrm{~B}$ & $3.633 \mathrm{~A}$ & $3.905 \mathrm{~B}$ & $y=2024+37,95 x-0,185 x^{2}$ & 1,00 \\
\hline IAC-370/11HT & $2.267 \mathrm{~B}$ & $2.916 \mathrm{~B}$ & $2.885 \mathrm{C}$ & $y=2380+5,147 x$ & 1,00 \\
\hline IAC-370/12HT & $3.450 \mathrm{~A}$ & $3.564 \mathrm{~A}$ & $4.518 \mathrm{~A}$ & $y=3309+8,90 x$ & 1,00 \\
\hline IAC-370/TEST & $2.385 \mathrm{~B}$ & $3.292 \mathrm{AB}$ & $3.565 \mathrm{~B}$ & $y=2490+9,83 x$ & 1,00 \\
\hline ITD-19/8AT & $2.431 \mathrm{~B}$ & $3.606 \mathrm{~A}$ & $3.538 \mathrm{~B}$ & $y=2430+29,95 x-0,173 x^{2}$ & 1,00 \\
\hline ITD-19/11HT & $3.227 \mathrm{~A}$ & $3.538 \mathrm{~A}$ & $4.195 \mathrm{~A}$ & $y=3169+8,064 x$ & 0,96 \\
\hline ITD-19/12HT & $2.609 \mathrm{~B}$ & $3.897 \mathrm{~A}$ & $3.825 \mathrm{AB}$ & $y=2608+32,78 x-0,188 x^{2}$ & 1,00 \\
\hline ITD-19/TEST & $3.230 \mathrm{~A}$ & $3.822 \mathrm{~A}$ & $3.823 \mathrm{AB}$ & $y=3328+4,94 x$ & 0,75 \\
\hline
\end{tabular}

${ }^{(1)}$ Letras iguais não diferem entre si pelo teste de Duncan, a $5 \%$ de probabilidade; as letras comparam os valores nas colunas, entre os isolados, dentro da mesma dose de $\mathrm{N}$ e do mesmo genótipo; os coeficientes de variação relativos a isolados, genótipos e doses foram 4,5, 9,7 e 10,8\%, respectivamente. 
$120 \mathrm{~kg} \mathrm{ha}^{-1}$ de $\mathrm{N}$, o que indica que altas doses de $\mathrm{N}$ não foram fator limitante para os efeitos benéficos causados por esses isolados. Outros fatores, como a produção de fitormônios, e não somente a FBN, podem ser responsáveis pelos benefícios propiciados por bactérias diazotróficas endofíticas (Baldani \& Baldani, 2005). Existem poucos relatos dos benefícios causados por bactérias do gênero Achromobacter. Recentemente, foi observado que um isolado de Achromobacter proporcionou resistência à salinidade (Mayak et al., 2004a) e resistência ao estresse hídrico (Mayak et al., 2004b) em plantas de tomate.

A massa de matéria seca e o acúmulo de $\mathrm{N}$ na parte aérea, assim como a produtividade de grãos, não foram beneficiadas pelas bactérias diazotróficas, no tratamento sem adubação nitrogenada, no experimento realizado em

Tabela 7. Massa de 1.000 grãos e N acumulado nos grãos, sob influência de três isolados de bactérias diazotróficas endofíticas e testemunha sem inoculação, independentemente do genótipo e da dose de $\mathrm{N}$ empregada, em Campinas, SP. Média de 24 repetições ${ }^{(1)}$.

\begin{tabular}{lcc}
\hline Isolado & $\begin{array}{c}\text { Massa de } \\
1.000 \text { grãos }(\mathrm{g})\end{array}$ & $\begin{array}{c}\mathrm{N} \text { acumulado no } \\
\text { grão }\left(\mathrm{kg} \mathrm{ha}^{-1}\right)\end{array}$ \\
\hline $8 \mathrm{AT}$ & $52,30 \mathrm{~A}$ & $70.251 \mathrm{~B}$ \\
$11 \mathrm{HT}$ & $52,42 \mathrm{~A}$ & $69.333 \mathrm{~B}$ \\
$12 \mathrm{HT}$ & $52,29 \mathrm{~A}$ & $80.713 \mathrm{~A}$ \\
TEST & $49,37 \mathrm{~B}$ & $72.561 \mathrm{~B}$ \\
\hline
\end{tabular}

${ }^{(1)}$ Letras iguais não diferem entre si pelo teste de Duncan, a $5 \%$ de probabilidade; para massa de 1.000 grãos os coeficientes de variação relativos a isolados, genótipos e doses foram 2,3, 8,5 e 5,3\%, respectivamente, e para $\mathrm{N}$ acumulado foram $4,2,10,6$ e $14,2 \%$, respectivamente.
Mococa, uma vez que a inoculação geralmente não substitui a adubação nitrogenada na cultura do trigo (Zambre et al., 1984; Saubidet et al., 2002); a associação planta-bactéria pode ter representado um alto custo para a planta, ao não proporcionar benefícios nessa condição.

Apesar da produtividade mais baixa obtida em Mococa, em relação ao experimento instalado em Campinas, foi possível verificar benefícios provenientes da inoculação, tendo-se obtido aumentos de até $26 \%$ na produtividade, na maior dose de $\mathrm{N}$ utilizada. No Rio Grande do Sul, foram obtidos aumentos de no máximo $20 \%$, em relação ao tratamento testemunha (Didonet et al., 1996) e, segundo Bashand \& Levanony (1990), aumento de $20 \%$ já pode ser considerado comercialmente significativo.

$\mathrm{O}$ teor de $\mathrm{N}$ nas sementes, da mesma forma que no experimento realizado em Campinas, e a massa de mil sementes não foram influenciados pelo emprego dos isolados utilizados, o que indica que a produtividade foi determinada pela quantidade de grãos e não pela massa deles.

A inoculação pode ser considerada uma prática pouco onerosa para a cultura do trigo, uma vez que, com base no preço do inoculante na forma de turfa, utilizado para a cultura da soja, o valor gasto com a inoculação seria de $\mathrm{R} \$ 5,40 \mathrm{ha}^{-1}$. Ao se considerar o preço do trigo de R\$ 350,00 a tonelada (Companhia Nacional de Abastecimento, 2006), aumentos acima de 15,43 kg ha-1 de grãos já justificariam a prática da inoculação.

Sabendo-se que o preço médio da tonelada da uréia é de $\mathrm{R} \$ 980,00$ (preço médio praticado no mercado de Campinas, SP), e o do trigo é R $\$ 350,00$, pode-se estabelecer o limite em que o acréscimo no custo do $\mathrm{N}$

Tabela 8. Produtividade de dois genótipos de trigo, do experimento de campo em Mococa, SP, no ano agrícola de 2002, em função de três doses de N, sem e com inoculação de isolados de bactérias diazotróficas endofíticas. Média de quatro repetições ${ }^{(1)}$.

\begin{tabular}{|c|c|c|c|c|c|}
\hline \multirow{2}{*}{ Tratamento } & \multicolumn{3}{|c|}{ Doses de $\mathrm{N}\left(\mathrm{kg} \mathrm{ha}^{-1}\right)$} & \multirow[t]{2}{*}{ Equação de regressão } & \multirow[t]{2}{*}{$\mathrm{R}^{2}$} \\
\hline & 0 & 60 & 120 & & \\
\hline \multicolumn{6}{|c|}{ Produtividade $\left(\mathrm{kg} \mathrm{ha}^{-1}\right)$} \\
\hline IAC-370/8AT & $1.004 \mathrm{~A}$ & $2.085 \mathrm{~B}$ & $2.639 \mathrm{~A}$ & $y=1092+13629 x$ & 0,96 \\
\hline IAC-370/11HT & $941 \mathrm{~A}$ & $2.277 \mathrm{AB}$ & $2.746 \mathrm{~A}$ & $\mathrm{y}=940,5+29,50 \mathrm{x}-0,120 \mathrm{x}^{2}$ & 1,00 \\
\hline IAC-370/12HT & $1.012 \mathrm{~A}$ & $2.264 \mathrm{AB}$ & $2.554 \mathrm{AB}$ & $\mathrm{y}=1012+28,86 \mathrm{x}-0,1333 \mathrm{x}^{2}$ & 1,00 \\
\hline IAC-370/TEST & $1.033 \mathrm{~A}$ & $2.530 \mathrm{~A}$ & $2.209 \mathrm{~B}$ & $y=1033+40,12 x-0,253 x^{2}$ & 1,00 \\
\hline ITD-19/8AT & $1.025 \mathrm{~A}$ & $2.325 \mathrm{~A}$ & $2.508 \mathrm{~A}$ & $y=1024+30,98 x-0,155 x^{2}$ & 1,00 \\
\hline ITD-19/11HT & $1.023 \mathrm{~A}$ & $2.253 \mathrm{~A}$ & $2.068 \mathrm{~B}$ & $y=1023+32,31 x-0,196 x^{2}$ & 1,00 \\
\hline ITD-19/12HT & $919 \mathrm{~A}$ & $1.679 \mathrm{~B}$ & $2.042 \mathrm{~B}$ & $y=983+9,358 x$ & 0,96 \\
\hline ITD-19/TEST & $1.119 \mathrm{~A}$ & $1.940 \mathrm{AB}$ & $2.204 \mathrm{AB}$ & $y=1211+9,04 x$ & 0,92 \\
\hline
\end{tabular}

(1)Letras iguais não diferem entre si pelo teste de Duncan, a 5\% de probabilidade; as letras comparam os valores nas colunas, entre os isolados, dentro da mesma dose de $\mathrm{N}$ e do mesmo genótipo; os coeficientes de variação relativos a isolados, genótipos e doses foram 9,4, 11,8 e 14,5\%, respectivamente. 
aplicado é compensado pelo acréscimo na produtividade de grãos, ou seja, a produtividade máxima econômica (Nogueira, 1997), que corresponde à quantidade aplicada de $\mathrm{N}$, que proporciona a máxima distância entre a linha de custo do insumo e a curva de resposta por unidade de área. Assim, a dose de N que proporciona o maior retorno econômico para o genótipo IAC-370, no experimento realizado em Campinas, seria de $120 \mathrm{~kg} \mathrm{ha}^{-1}$ de $\mathrm{N}$, para o tratamento com o isolado IAC-HT-12 e, também, para o tratamento testemunha, uma vez que as respostas à adição de $\mathrm{N}$ foram lineares, com o emprego desses dois tratamentos, e os coeficientes lineares das equações ajustadas (Tabela 6) são maiores que a relação de preços entre a tonelada de trigo e da uréia. Ao se considerar o custo do inóculo de $\mathrm{R} \$ 5,40 \mathrm{ha}^{-1}$, obtem-se lucro de $\mathrm{R} \$ 328,00 \mathrm{ha}^{-1}$ com o emprego do isolado IAC-HT-12, em relação ao tratamento testemunha.

No experimento realizado em Mococa, ao ser calculada a produtividade máxima econômica, para o genótipo IAC-370, obteve-se que a dose de $\mathrm{N}$ que proporcionaria maior retorno econômico seria a de $120 \mathrm{~kg} \mathrm{ha}^{-1}$ de N, com o emprego do isolado IAC-AT-8, de $97 \mathrm{~kg} \mathrm{ha}^{-1}$ com o isolado IAC-HT-11, e de $67 \mathrm{~kg} \mathrm{ha}^{-1}$ para o tratamento testemunha, sendo que a produtividade obtida com a inoculação nas doses acima mencionadas não propiciariam lucro em relação ao tratamento testemunha. Entretanto, considerando-se somente a produtividade obtida na maior dose de $\mathrm{N}$ utilizada (120 kg ha-1 de N), seriam obtidos lucros de $\mathrm{R} \$ 145,00 \mathrm{ha}^{-1}$ com o isolado IAC-AT- 8 e de $\mathrm{R} \$ 182,00$ ha $^{-1}$ com o isolado IAC-HT-11, em relação ao tratamento testemunha. As plantas na presença do isolado IAC-AT- 8 produziram $4 \mathrm{~kg}$ de grãos acima da testemunha por quilo de $\mathrm{N}$ adicionado, e do isolado IAC-HT- $11,5 \mathrm{~kg}$ acima da testemunha, o que demonstra maior eficiência de utilização do $\mathrm{N}$ na maior dose utilizada.

Apesar de não ter sido observado efeito significativo da inoculação para produção de grãos, no genótipo ITD-19, por meio do cálculo da produtividade máxima econômica, observou-se que o agricultor obteria lucro com a inoculação em ambas as localidades. Com o emprego do isolado IAC-HT-11, no experimento realizado em Campinas, a dose que proporcionaria o maior retorno econômico também seria a de $120 \mathrm{~kg} \mathrm{ha}^{-1}$ de $\mathrm{N}$, o lucro obtido com a inoculação seria de $\mathrm{R} \$ 125,00 \mathrm{ha}^{-1}$, em relação ao tratamento testemunha, nessa mesma dose de N. Em Mococa, a produtividade máxima econômica seria obtida na dose de $80 \mathrm{~kg} \mathrm{ha}^{-1}$ de $\mathrm{N}$, com o emprego do isolado IAC-AT-8, de $67 \mathrm{~kg} \mathrm{ha}^{-1}$ com o isolado IAC-HT-11 e de $120 \mathrm{~kg} \mathrm{ha}^{-1}$ na testemunha, e propiciaria um lucro de $\mathrm{R} \$ 187,00$ e de $\mathrm{R} \$ 143,00 \mathrm{ha}^{-1}$, respectivamente, em relação à testemunha.

Um dos pontos cruciais para seleção e manejo desses diazotróficos é a especificidade planta-bactéria, conforme revisado por Baldani \& Baldani (2005). No presente trabalho, foi observado que apesar desses isolados terem sido obtidos das raízes desinfestadas superficialmente do genótipo ITD-19 (Sala et al., 2005), somente no genótipo IAC-370 foi obtido aumento significativo da produtividade, com a inoculação em relação ao tratamento testemunha, e esse efeito se repetiu nas duas localidades estudadas.

Esse genótipo foi beneficiado pela inoculação, mesmo em altas doses de fertilizante nitrogenado, possivelmente, porque é altamente responsivo à adição de $\mathrm{N}$ e apresenta alto rendimento de grãos em condições favoráveis (Trigo..., 1999). Ainda, esse efeito pode ter ocorrido em conseqüência de uma melhor interação planta-bactéria diazotrófica, nessa condição, uma vez que os isolados utilizados foram obtidos de plantas de trigo na presença de adubação nitrogenada (Sala et al., 2005).

Existem relatos de benefícios oriundos da inoculação de Azospirillum em plantas de trigo, com a adição de fertilizante nitrogenado, que variam de $15 \mathrm{~kg} \mathrm{ha}^{-1}$ até aproximadamente $160 \mathrm{~kg} \mathrm{ha}^{-1}$ de N (Zambre et al., 1984; Didonet et al., 1996, 2000; Dalla Santa et al., 2004). Existem evidências de que em plantas de trigo a inoculação não substitui o adubo nitrogenado, porém, promove a melhor absorção e utilização do $\mathrm{N}$ disponível (Saubidet et al., 2002). Já foi observado que os isolados utilizados promovem aumento no crescimento das raízes de plantas de trigo, em condições gnotobióticas (Sala et al., 2005), e que o efeito estimulatório no desenvolvimento das raízes, nos primeiros estádios de desenvolvimento da planta, pode ser responsável pelo efeito positivo da inoculação (Mertens \& Hess, 1984). A maior absorção de $\mathrm{N}$ pelas raízes pode ocorrer em razão da produção, pela bactéria, de auxinas, citoquininas e giberelinas (Baldani \& Baldani, 2005) e, ainda, graças ao aumento no número de raízes e pêlos radiculares (Dobbelaere et al., 1999), o que permite melhor exploração do solo e benefícios em condições de estresse hídrico em trigo (Creus et al., 2004).

Este é o primeiro trabalho que relata o efeito da inoculação, em campo, dos gêneros Achromobacter 
e Zoogloea, em plantas de trigo, com resultados benéficos para essa cultura e aumento de sua produtividade.

\section{Conclusões}

1. Há aumento de produção com a inoculação de Azospirillum, Achromobacter e Zoogloea na cultura do trigo.

2. Não há especificidade dos genótipos de trigo empregados e essas novas bactérias endofíticas.

3. O local de cultivo influencia as respostas obtidas com a inoculação.

4. O maior incremento na produtividade de grãos é obtido na ausência de $\mathrm{N}$ adicional.

5. A inoculação proporciona maior rentabilidade à cultura do trigo.

\section{Agradecimentos}

À técnica Rosana Gierts Gonçalves, ao Centro Experimental Central do Instituto Agronômico/Apta e à Unidade de Pesquisa e Desenvolvimento de Mococa, pelo auxílio na realização dos experimentos de campo; à Capes pela bolsa de estudos concedida; à Fapesp, pelo auxílio ao projeto.

\section{Referências}

BALDANI, J.I.; BALDANI, V.L.D. History on the biological nitrogen fixation research in graminaceous plants: special emphasis on the Brazilian experience. Anais da Academia Brasileira de Ciências, v.77, p.549-579, 2005.

BASHAND, Y.; LEVANONY, H. Current status of Azospirillum inoculation technology: Azospirillum as a challenge for agriculture. Canadian Journal of Microbiology, v.36, p.591-605, 1990.

BERTRAND, H.; PLASSARD, C.; PINOCHET, X.; TOURAINE, B.; NORMAND, P.; CLEYET-MAREL, J.C. Stimulation of the ionic transport system in Brassica napus by a plant growthpromoting rhizobacterium (Achromobacter sp.). Canadian Journal of Microbiology, v.46, p.229-236, 2000.

BILAL, R.; MALIK, K. Isolation and identification of a $\mathrm{N}_{2}$-fixing Zoogloea-forming bacterium from kallar grass histoplane. Journal of Applied Bacteriology, v.62, p.289-294, 1987.

BISSOTO, V. Algumas considerações sobre a cultura do trigo. In: REUNIÃO DA COMISSÃO SUL-BRASILEIRA DE PESQUISA DE TRIGO, 36., Passo Fundo. Anais. Passo Fundo: Embrapa Trigo, 2004. Disponível em: <http://www.cnpt.embrapa.br/culturas/trigo/ rcsbpt04/index.htm>. Acesso em: 18 maio 2007.

BREMNER, J.M. Total nitrogen. In: BLACK, C.A. (Ed.). Methods of soil analysis. Madison: American Society of Agronomy, 1965. p.1149-1178.
COMPANHIA NACIONAL DE ABASTECIMENTO. Companhia Nacional de Abastecimento. Disponível em: <http:/ /www.conab.gov.br/download/comercializacao/precos_com/ precos_2006/COMU_406.doc>. Acesso em: 4 ago. 2006.

CREUS, C.M.; SUELDO, R.J.; BARASSI, C.A. Water relations and yield in Azospirillum-inoculated wheat exposed to drought in the field. Canadian Journal of Botany, v.82, p.273-281, 2004.

DALLA SANTA, O.R.; HERNÁNDEZ, R.F.; ALVAREZ, G.L.M.; RONZELLI JUNIOR, P.; SOCCOL, C.R. Azospirillum sp. inoculation in wheat, barley and oats seeds greenhouse experiments. Brazilian Archives of Biology and Technology, v.47, p.843-850, 2004.

DIDONET, D.A.; LIMA, O.S.; CANDATEN, M.H.; RODRIGUES, O. Realocação de nitrogênio e de biomassa para os grãos, em trigo submetido a inoculação de Azospirillum. Pesquisa Agropecuária Brasileira, v.35, p.401-411, 2000.

DIDONET, D.A.; RODRIGUES, O.; KENNER, M.H. Acúmulo de nitrogênio e de massa de matéria seca em plantas de trigo inoculadas com Azospirillum brasilense. Pesquisa Agropecuária Brasileira, v.31, p.645-651, 1996.

DOBBELAERE, S.; CROONENBORGHS, A.; THYS, A.; BROEK, A.V.; VANDERLEYDEN, J. Phytostimulatory effect of Azospirillum brasilense wild type and mutant strains altered in IAA production on wheat. Plant and Soil, v.212, p.155-164, 1999.

DOBBELAERE, S.; CROONENBORGHS, A.; THYS, A.; PTACEK, D.; OKON, Y.; VANDERLEYDEN, J. Effect of inoculation with wild type Azospirillum brasilense and A. irakense strains on development and nitrogen uptake of spring wheat and grain maize. Biology and Fertility of Soils, v.36, p.284-297, 2002.

DÖBEREINER, J.; BALDANI, J.I.; BALDANI, V.L.D. Como isolar e identificar bactérias diazotróficas de plantas não leguminosas. Brasília: Embrapa- SPI; Itaguaí: Embrapa-CNPAB, 1995. 60p.

HALLMANN, J.; QUADT-HALLMANN, A.; MAHAFFEE, W.F.; KLOEPPER, J.W. Bacterial endophytes in agricultural crops. Canadian Journal of Microbiology, v.43, p.895-914, 1997.

HASHIDOKO, Y.; TADA, M.; TAHARA, S. Soft gel medium solidified with gellan gum for preliminary screening for rootassociating, free-living nitrogen-fixing bacteria inhabiting the rhizoplane of plants. Bioscience, Biotechnology, and Biochemistry, v.66, p.2259-2263, 2002.

LADHA, J.K.; PATHAK, H.; KRUPNIK, T.J.; SIX, J.; KESSEL, C.V. Efficiency of fertilizer nitrogen in cereal production: retrospects and prospects. Advances in Agronomy, v.87, p.85-156, 2005.

MAYAK, S.; TIROSH, T.; GLICK, B.R. Plant growth-promoting bacteria that confer resistance in tomato plants to salt stress. Plant Physiology and Biochemistry, v.42, p.565-572, 2004a.

MAYAK, S.; TIROSH, T.; GLICK, B.R. Plant growth-promoting bacteria that confer resistance to water stress in tomatoes and peppers. Plant Science, v.166, p.525-530, 2004b.

MERTENS, T.; HESS, D. Yield increases in spring wheat (Triticum aestivum L.) inoculated with Azospirillum lipoferum under greenhouse and field conditions of temperate region. Plant and Soil, v.82, p.87-99, 1984.

MIRZA, M.S.; MEHNAZ, S.; ORMAND, P.; PRIGENTCOMBARET, C.; MOENNE-LOCCOZ, Y.; BALLY, R.; MALIK, 
K.A. Molecular characterization and PCR detection of a nitrogenfixing Pseudomonas strain promoting rice growth. Biology and Fertility of Soils, v.43, p.163-170, 2006.

NOGUEIRA, M.C.S. Estatística experimental aplicada à experimentação agronômica. Piracicaba: Esalq, 1997. 250p.

OKON, Y.; LABANDERA-GONZALES, C.A. Agronomic applications of Azospirillum: an evaluation of 20 years worldwide field inoculation. Soil Biology and Biochemistry, v.26, p.15911601, 1994.

RAIJ, B. van; CANTARELLA, H.; QUAGGIO, J.A.; FURLANI, A.M.C. Recomendações de adubação e calagem para o Estado de São Paulo. Campinas: IAC, 1997. 285p. (IAC. Boletim, 100).

REIS, V.M.; BALDANI, J.I.; BALDANI, V.L.; DÖBEREINER, J. Biological dinitrogen fixation in gramineae and palm trees. Critical Reviews in Plant Sciences, v.19, p.227-247, 2000.

SALA, V.M.R. Atividade microbiana do solo e a interação de diazotróficos endofíticos e fungos micorrízicos arbusculares na cultura do trigo. 2002. 123p. Dissertação (Mestrado) - Escola Superior de Agricultura Luiz de Queiroz, Piracicaba.

SALA, V.M.R.; FREITAS, S.S.; DONZELI, V.P.; FREITAS, J.G.; GALLO, P.B.; SILVEIRA, A.P.D. Ocorrência e efeito de bactérias diazotróficas em genótipos de trigo. Revista Brasileira de Ciência do Solo, v.29, p.345-352, 2005.

SAUBIDET, M.I.; FATTA, N.; BARNEIX, A.J. The effect of inoculation with Azospirillum brasilense on growth and nitrogen utilization by wheat plants. Plant and Soil, v.245, p.215-222, 2002.

TRIGO IAC-370 Armageddon. O Agronômico, v.51, p.38, 1999.

TSAVKELOVA, E.A.; KLIMOVA, S.Y.; CHERDYNTSEVA, T.A.; NETRUSOV, A.I. Microbial producers of plant growth stimulators and their practical use: a review. Applied Biochemistry and Microbiology, v.42, p.117-126, 2006.

ZAMBRE, M.A.; KONDE, B.K.; SONAR, K.R. Effect of Azotobacter chroococcum and Azospirillum brasilense inoculation under graded levels of nitrogen on growth and yield of wheat. Plant and Soil, v.79, p.61-67, 1984.

Recebido em 17 de novembro de 2006 e aprovado em 3 de maio de 2007 